\title{
Diagnóstico de febre catarral maligna em bovinos do Uruguai ${ }^{1}$
}

\author{
Marcela Preliasco ${ }^{2 *}$, María C. Easton ${ }^{2}$, Cecilia Paullier², Rodolfo Rivero ${ }^{3}$, Danny \\ Franciele S.D. Moraes ${ }^{4}$, Isabela Godoy ${ }^{4}$, Valéria Dutra ${ }^{4}$ e Luciano Nakazato ${ }^{4}$
}

\begin{abstract}
Preliasco M., Easton M.C., Paullier C., Rivero R., Moraes D.F.S.D., Godoy I., Dutra V. \& Nakazato L. 2013. [Diagnosis of malignant catarrhal fever in cattle in Uruguay.] Diagnóstico de Febre Catarral Maligna em bovinos do Uruguai. Pesquisa Veterinária Brasileira 33(1):52-56. Laboratorio Central "Miguel C. Rubino", División de Laboratorios Veterinarios del Ministerio de Ganadería Agricultura y Pesca de Uruguay, Ruta 8 km, C.P. 12.100, Montevideo, 17.500, Uruguay. E-mail: mpreliasco@mgap.gub.uy

A retrospective study of 14 outbreaks of malignant catarrh fever (MCF) in cattle detected between 1999 and 2011 was performed based upon the files of the DILAVE "Miguel C. Rubino" Montevideo Pathology Laboratory. Epidemiological data, clinical presentation, gross and histopathological lesions were analyzed. PCR was used on central nervous system samples of 12 bovines for the detection of ovine herpesvirus type 2 (OvHV-2). The outbreaks occurred mainly in spring and summer in the northern region of the country. Sixty four percent (9/14) were individual episodes of the disease while five cases were collective, with morbidity and mortality rates were $2-5 \%$, being the lethality $100 \%$ in all the reports. In $50 \%$ of the outbreaks the direct contact between cattle and sheep was confirmed, while there was not such information in the rest of the cases. Predominant clinical signs were bilateral corneal opacity, conjunctivitis, ocular and nasal mucopurulent discharge, and nervous syndrome. The most frequent necropsy findings were bilateral corneal opacity and inflammatory lesions in the mucosa. Histopathological findings were characterized by systemic necrotizing panvasculite. It was possible to detect the etiological agent by PCR in 5 out of 12 cases examined.
\end{abstract}

INDEX TERMS: Malignant catarrhal fever, ovine herpesvirus type 2, cattle, Uruguay.

RESUMO.- Foi realizado um estudo retrospectivo de 14 focos de febre catarral maligna (FCM) em bovinos, detectados nos anos de 1999-2011, a partir dos arquivos da Seção Anatomia Patológica da Divisão de Laboratórios Veterinários (DILAVE) "Miguel C. Rubino" Montevideo. Foram analisados os dados epidemiológicos, apresentação clínica e lesões macroscópicas e histopatológicas. Para a detecção do herpesvírus ovino tipo 2 (OvHV-2) foi utilizada a técnica

\footnotetext{
${ }^{1}$ Recebido em 2 de outubro de 2012.

Aceito para publicação em 7 de novembro de 2012.

${ }^{2}$ Laboratorio Central "Miguel C. Rubino", División de Laboratorios Veterinarios del Ministerio de Ganadería Agricultura y Pesca de Uruguay, Ruta 8 km, C.P. 12.100, Montevideo, 17.500, Uruguay. *Autor para correspondência: mpreliasco@mgap.gub.uy

${ }^{3}$ Laboratorio Regional Noroeste "Miguel C. Rubino", División de Laboratorios Veterinarios del Ministerio de Ganadería Agricultura y Pesca de Uruguay, C.P. 60.000, Paysandú, C.C. 57037, Uruguay.

${ }^{4}$ Departamento de Clínica Médica Veterinária, Universidade Federal de Mato Grosso (UFMT), Av. Fernando Corrêa s/n, Coxipó, Cuiabá, MT 78060900, Brasil.
}

de PCR sobre as amostras do sistema nervoso central de bovinos de 12 focos. Os surtos ocorreram principalmente nos meses de primavera e verão, na região norte do país. Em 64\% (9/14) dos focos ocorreram episódios individuais da enfermidade, enquanto que os casos coletivos foram 5 , nos quais a morbidade e mortalidade oscilaram entre $2 \% \mathrm{e}$ $5 \%$, sendo a letalidade $100 \%$ em todos os relatos. Em 50\% dos surtos foi confirmado o contato direto entre bovinos e ovinos, enquanto no restante não havia tal informação. Clinicamente predominaram os sinais de opacidade bilateral da córnea, conjuntivite, secreção nasal e ocular mucopurulenta, assim como a síndrome nervosa. Os achados de necropsia mais frequentes foram opacidade bilateral da córnea e lesões inflamatórias nas mucosas. Os achados histopatológicos caracterizaram-se por panvasculite necrótica sistêmica. Foi possível detectar o agente etiológico por PCR em 5 dos 12 casos analisados.

TERMOS DE INDEXAÇÃO: Febre catarral maligna, herpesvírus ovino tipo 2, bovinos, Uruguai. 


\section{INTRODUÇÃO}

A febre catarral maligna (FCM) é uma enfermidade infecciosa, linfoproliferativa, pansistêmica, altamente letal, de distribuição mundial que afeta numerosas espécies de mamíferos do grupo Artiodactyla, incluindo bovinos, búfalos, bisontes, veados, antílopes, suínos e outros (Plowright et al. 1960, Hänichen et al. 1998, Schultheiss et al. 2000, Barros et al. 2006, Li et al. 2006, Alcaraz et al. 2009). É causada por vírus pertencentes ao gênero Macavirus, subfamília Gammaherpesvirinae da ordem Herpesvírus (Davison et al. 2009). Atualmente existem nove espécies de vírus compondo esse grupo (Davison et al. 2009), no entanto, estão associados a ocorrência da doença em bovinos o alcelaphine herpesvírus-1 e herpesvírus ovino tipo 2 (Alcaraz et al. 2009, Davison et al. 2009, Dewals et al. 2011). Esses vírus têm hospedeiros imunologicamente adaptados, os quais não manifestam a enfermidade clínica, tornando-se portadores assintomáticos que desempenham um importante papel na transmissão do agente para espécies suscetíveis (Hüssy et al. 2002).

Herpesvírus ovino tipo 2 (OvHV-2) é responsável pela FCM associada a ovinos. Neste caso, os ovinos domésticos (Ovis aries) são hospedeiros naturais, manifestando a infecção subclínica, sendo capazes de transmitir o vírus a espécies suscetíveis (Li et al. 2004, Taus et al. 2010, Dewals et al. 2011). Considera-se que a principal via de transmissão desse vírus ocorre pelo contato direto com aerossóis das secreções nasais de ovinos infectados, dessa forma, o aparecimento de surtos em bovinos está relacionado com áreas de pastoreio misto entre ovinos e bovinos (Li et al. 2004, Dutra 2010a).

Os casos de FCM associados a ovinos geralmente ocorrem de forma esporádica. Apesar disso, também ocorrem surtos que alcançam altas taxas de morbidade e mortalidade $(2-50 \%)$ sendo a letalidade geralmente de $100 \%$ (Schultheiss et al. 2000, Rech et al. 2005, Barros et al. 2006, Macêdo et al. 2007, Radostitis et al. 2007, Dutra 2009, 2010b).

No Uruguai, realiza-se o diagnóstico de FCM pela histopatología relacionado com o quadro clinico e dados epidemiológicos. No entanto, até o momento, não se tem realizado a identificação do agente causal. A detecção de OvHV-2 baseia-se em técnicas de amplificação de DNA (Li et al. 2001, Hüssy et al. 2002, Li et al. 2004, Mendonça et al. 2008, Alcaraz et al. 2009).

O objetivo do presente estudo é descrever os focos de febre catarral maligna em bovinos, correspondentes às amostras recebidas pela Seção Anatomia Patológica do Laboratorio DILAVE "Miguel C. Rubino" Montevideo, no período de 1999-2011, assim como a confirmação da presença do agente etiológico (OvHV-2) através da técnica de PCR.

\section{MATERIAL E MÉTODOS}

Foi realizado um estudo retrospectivo de 14 focos de FCM em bovinos, detectados entre os anos de 1999 e 2011, a partir dos arquivos da Seção Anatomia Patológica do Laboratorio DILAVE "Miguel C. Rubino" Montevideo. Foram analisados os dados epidemiológicos, apresentação clínica, lesões macroscópicas e histopatológicas.

Para a detecção de OvHV-2 foi utilizada a técnica de PCR. Foram realizados cortes com espessura de 10 micras nos blocos parafinados de diversas regiões do sistema nervoso central, correspondentes a 12 casos de 12 focos com diagnóstico de FCM por histopatologia. As amostras foram processadas e submetidas à técnica de PCR no Laboratório de Biologia Molecular do Hospital Veterinário da Universidade Federal de Mato Grosso, Cuiabá, Brasil, seguindo a metodologia descrita por Mendonça et al. (2008). Não foi realizada a PCR nas amostras correspondentes aos focos 1 (Artigas, outubro 2011) e 10 (Paysandú, abril de 2003) pelo fato dos materiais não se encontrarem em condições adequadas para serem processados por tal técnica.

\section{RESULTADOS}

Os principais dados epidemiológicos dos 14 focos de FCM detectados no período estudado estão resumidos no Quadro 1 . Os surtos ocorreram principalmente na região norte do país, sendo $57 \%$ (8/14) localizados nos departamentos de Artigas, Salto e Paysandú. Os focos aconteceram principalmente nos meses de primavera e verão, de setembro a fevereiro. Em 64\% (9/14) dos focos ocorreram episódios individuais da enfermidade, enquanto que os casos coleti-

\begin{tabular}{|c|c|c|c|c|c|c|c|c|}
\hline $\mathrm{ID}^{\mathrm{a}}$ & Departamento & Período & Sexo & Idade & Raça & $\begin{array}{c}\text { Contato } \\
\text { ovinos }\end{array}$ & Doentes & № total ${ }^{\mathrm{b}}$ \\
\hline 1 & Artigas & Out/2011 & Macho & $<1$ ano & Hereford & s.d & 1 & 130 \\
\hline 2 & Durazno & Jan/2011 & Macho & 1-2 anos & Hereford & Sim & 8 & 350 \\
\hline 3 & Salto & Set/2010 & Macho & $>2$ anos & Hereford & s.d & 1 & 85 \\
\hline 4 & Artigas & Jul/2009 & Fêmea & 1-2 anos & Hereford & Sim & 1 & s.d. \\
\hline 5 & Tacuarembó & Nov/2008 & Fêmea & $>2$ anos & Hereford & Sim & 7 & 180 \\
\hline 6 & Salto & Set/2008 & Fêmea & 1-2 anos & Cruza & Sim & 1 & 120 \\
\hline 7 & Rivera & Fev/2006 & Macho & 1-2 anos & Hereford & s.d & 1 & 220 \\
\hline 8 & Artigas & Out/2003 & Fêmea & 1-2 anos & Hereford & s.d & 6 & 300 \\
\hline 9 & Paysandú & Abr/2003 & Fêmea & 1-2 anos & Cruza & s.d & 1 & 175 \\
\hline 10 & Paysandú & Fev/2003 & Macho & $>2$ anos & Hereford & s.d & 3 & 150 \\
\hline 11 & Montevideo & Jan/2002 & Fêmea & $>2$ anos & Jersey & Sim & 1 & 2 \\
\hline 12 & Salto & Jan2000 & $\begin{array}{l}\text { Fêmea } \\
\text { Macho }\end{array}$ & $>2$ anos & Hereford & Sim & 5 & 100 \\
\hline 13 & Florida & Dez/1999 & Macho & 1-2 anos & Cruza & s.d & 1 & s.d. \\
\hline 14 & Lavalleja & $\mathrm{Abr} / 1999$ & Macho & 1-2 anos & A.A. & Sim & 1 & 300 \\
\hline
\end{tabular}

adentificação do surto; ${ }^{\mathrm{b}}$ número total de animais em risco; s.d. = sem dados. 


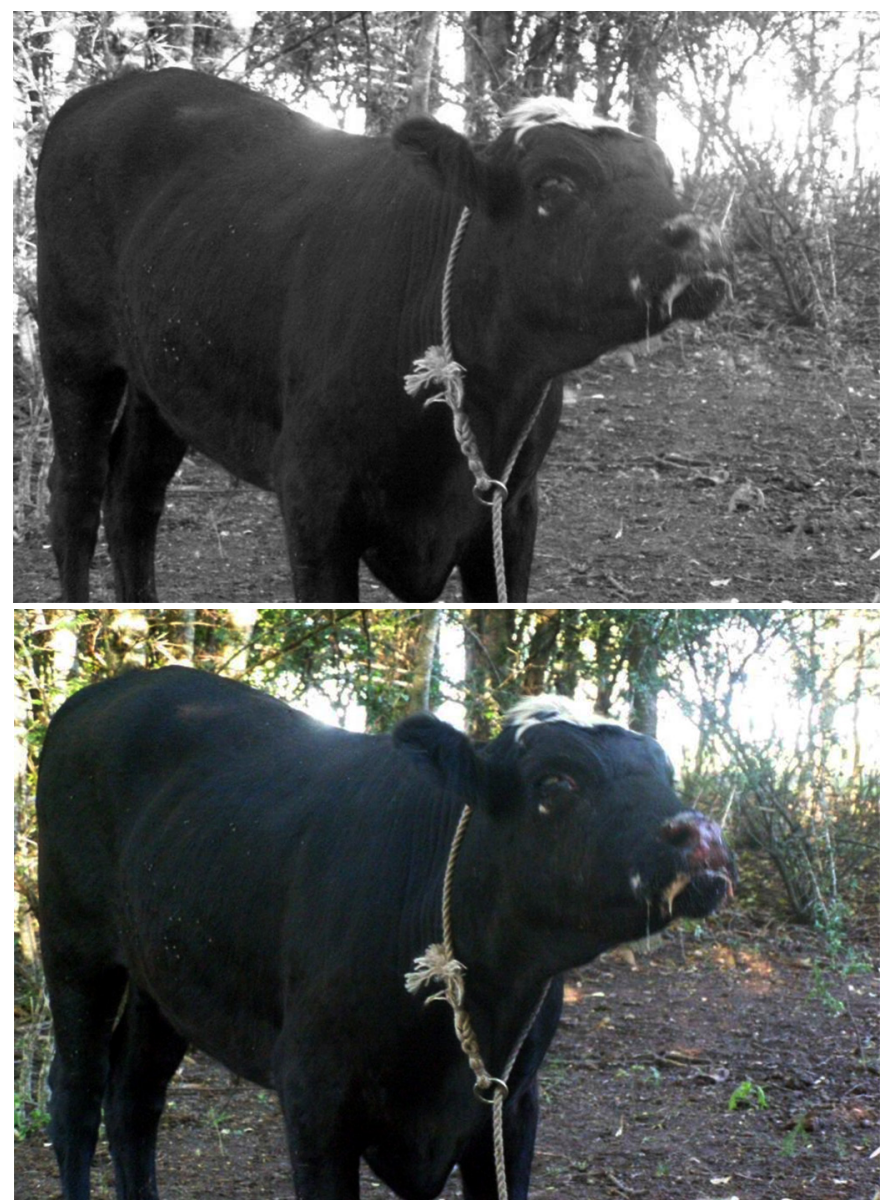

Fig.1. Bovino macho com depressão, opacidade corneal bilateral, fotofobia, secreção nasal e ocular mucopurulenta.

vos foram 5 , nos quais a morbidade e mortalidade oscilaram entre $2-5 \%$, sendo a letalidade $100 \%$ em todos os relatos. A doença ocorreu principalmente em novilhos, vacas e novilhas de raças de corte. Em $50 \%$ dos surtos foi confirmado o contato direto de bovinos com ovinos, enquanto no restante não havia tal informação.

Os principais sinais clínicos caracterizaram-se por opacidade bilateral da córnea, secreção mucopurulento nasal e ocular, conjuntivite, fotofobia e salivação intensa, sendo este a síndrome predominante, detectada em $90 \%$ dos casos estudados (Fig.1). Os sinais nervosos ocorreram em $80 \%$ dos casos e incluíram afastamento do rebanho, andar em círculos, depressão, anorexia, tremores musculares, cegueira, agressividade, ataxia dos membros posteriores, decúbito, convulsão e opistótonos. Também foram registradas febre e diarréia em $35 \%$ dos focos e linfoadenomegalia generalizada em $15 \%$.

Os achados de necropsias caracterizam-se por opacidade da córnea e conjuntivite, lesões inflamatórias erosivas, necróticas e ulcerativas das mucosas do trato respiratório e digestivo (narinas, cornetos nasais, gengivas, palato, língua, faringe, esôfago, traquéia, abomaso e intestinos), linfoadenomegalia, enterite catarral, congestão e edema pulmonar, focos esbranquiçados de aproximadamente $3 \mathrm{~mm}$ de diâmetro distribuídos na superfície e no interior do parênquima dos rins e fígado, áreas de congestão a nível do endocárdio. Também foram observadas hemorragias generalizadas, inflamação purulenta dos órgãos respiratórios, áreas de consolidação pulmonar, coleção de abundante líquido sanguinolento/ hemopurulento nas cavidades pericárdica e abdominal, presença de lesões erosivas longitudinais com desprendimento parcial da mucosa e formação de pseudomembranas no nível da cavidade bucal, esôfago e reto, artrite nos membros anteriores e posteriores e hemorragias na base do encéfalo.

Histologicamente, os principais achados histológicos caracterizam-se por vasculite e perivasculite generalizadas, com infiltração das células mononucleares e necrose fibrinoide dos vasos sanguíneos (Fig.2 e 3). As lesões se encontravam distribuídas de maneira difusa, cobrindo todas as regiões anatômicas do sistema nervoso central. Além desses achados, observou-se nefrite intersticial não supurativa, hepatite e degeneração gordurosa do fígado, bronquite supurativa, congestão e hemorragia pulmonar, miocardite, adenite hemorrágica, baço com focos de necrose difusa na região medular, inflamação e úlceras na língua, esôfago, abomaso e intestinos e cistite hemorrágica com necrose epitelial.

Dos 12 casos em que foi realizada a PCR, cinco foram positivos para OvHV-2. Os focos estudados assim como as regiões do sistema nervoso central (SNC) analisadas e os resultados estão descritos no Quadro 2.
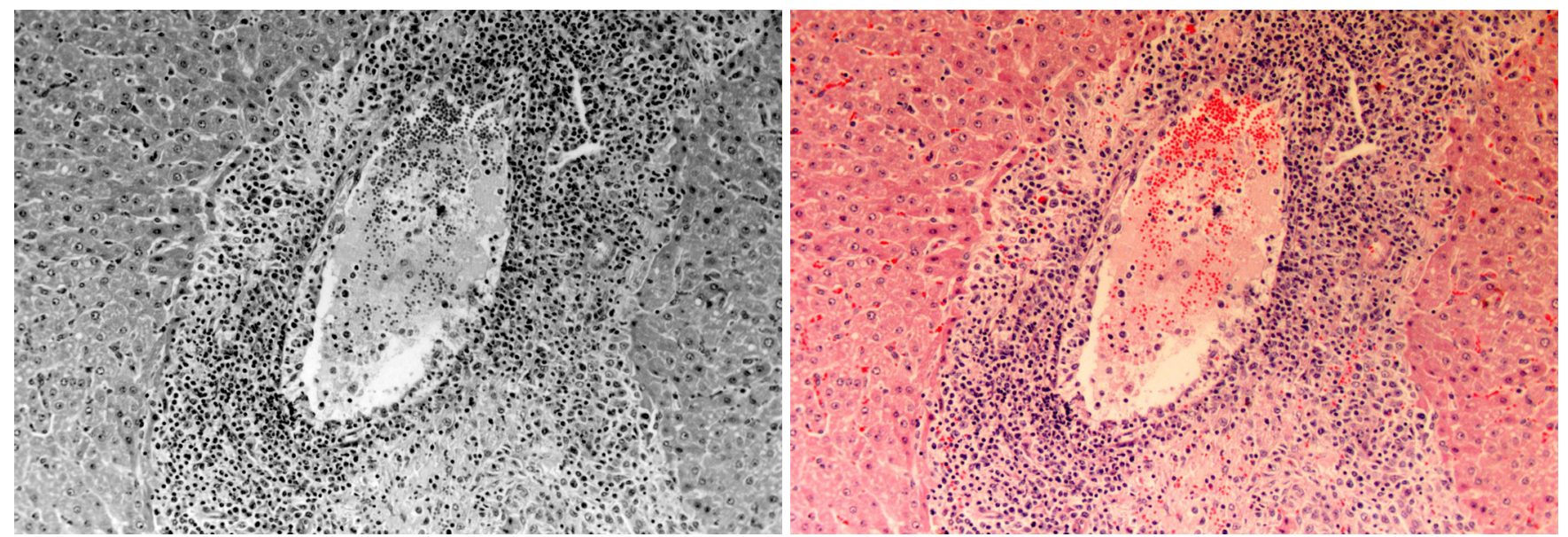

Fig.2. Hepatite com vasculitis necrotizante fibrinoide em bovino. HE, obj.20x. 

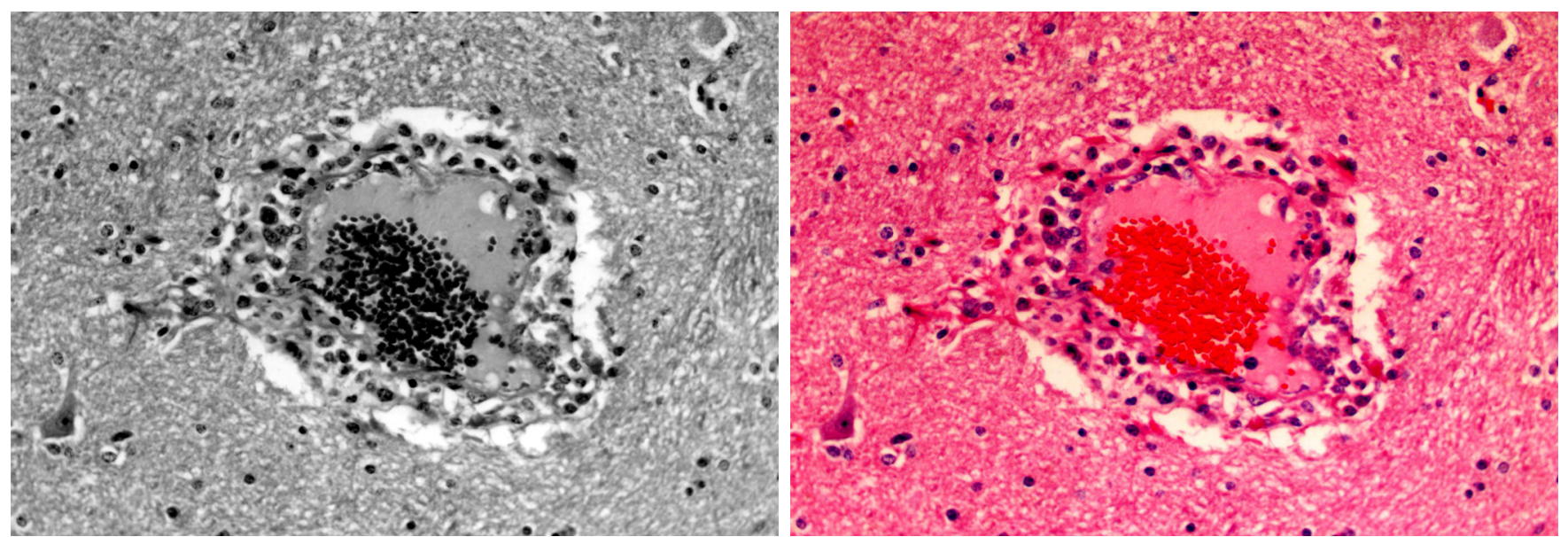

Fig.3. Encefalite associada à vasculitis necrotizante caracterizada por infiltração do endotélio vascular e necrose fibrinoide em tálamo de bovino. HE, obj.40x.

Quadro 2. Resultados da PCR para a detecção de OvHV-2 nas amostras do sistema nervoso central fixadas e embebidas em parafina

\begin{tabular}{cclc}
\hline ID $^{\text {a }}$ & Ano & Região do sistema nervoso analisada & Resultado \\
\hline 2 & 2011 & Córtex occipital, Cápsula interna & Positivo \\
3 & 2010 & Hipocampo, Mesencéfalo & Positivo \\
4 & 2009 & Córtex frontal, Mesencéfalo & Positivo \\
5 & 2008 & Mesencéfalo, Ponte & Negativo \\
6 & 2008 & Mesencéfalo & Negativo \\
7 & 2006 & Córtex & Negativo \\
8 & 2003 & Cerebelo & Negativo \\
9 & 2003 & Córtex & Negativo \\
11 & 2002 & Córtex & Positivo \\
12 & 2000 & Cápsula interna, Tálamo, Mesencéfalo & Positivo \\
13 & 1999 & Mesencéfalo, Córtex & Negativo \\
14 & 1999 & Obex & Negativo
\end{tabular}

a Identificação do surto.

\section{DISCUSSÃO}

As análises da informação epidemiológica coletada dos diferentes focos permitem sugerir que o comportamento da FCM no período estudado foi similar ao reportado pela literatura da região (Rech et al. 2005, Barros et al. 2006, Macêdo et al. 2007, Campero et al. 2008, Mendonça et al. 2008).

A maioria dos relatos (93\%) ocorreu no norte do país, região onde se concentra a produção nacional de ovinos (Censo Estadístico Agropecuario DIEA 2011). Foi possível confirmar o contato direto com os ovinos em $50 \%$ dos surtos relatados. Embora não haja tal informação para o restante dos focos, a literatura sugere que o contacto direto das espécies suscetíveis com os ovinos infectados não é uma condição necessária para o aparecimento da doença, existindo relatos de FCM em estabelecimentos distante cerca de $5 \mathrm{~km}$ da fazenda com criação ovina mais próxima (Li et al. 2008). A ausência de ovinos no ambiente ao momento do aparecimento da doença em bovinos pode ser explicada por o prolongado período de incubação que este vírus pode apresentar para manifestar a doença clinicamente (três semanas a seis meses) (Macêdo et al. 2007). Alem disso, estes vírus tem a capacidade de permanecerem latentes em animais infectados, até que um estado de imunossupressão os reativa, desencadeando os surtos (Macêdo et al. 2007). Também deve ser notado que outras espécies animais podem ser vetores deste vírus como cervos selvagens e caprinos, o que pode explicar a ocorrência de surtos em rebanhos bovinos que nunca estiveram em contato direto com ovinos (Hänichen et al. 1998, Li et al. 2001, Macêdo et al. 2007).

Bovinos de raça de corte foram os principais afetados. Isto pode estar relacionado com fato de que os sistemas de produção extensivos são predominantes no norte do país, onde a criação conjunta de bovinos de corte e ovinos é uma prática comum. Os sistemas de produção leiteira concentram-se nas regiões centro e sul, zonas de melhor aptidão de forragens, onde a população de ovinos é pequena (00,3\%) (Censo Estadístico Agropecuario DIEA 2011).

Os surtos estudados ocorreram principalmente nos meses de primavera e verão. Esses dados coincidem com estudos epidemiológicos anteriores (Rech et al. 2005, Mendonça et al. 2008, Dutra 2009, 2010b). A probabilidade de transmissão de OvHV-2 está estritamente relacionada com a quantidade de vírus circulante (Li et al. 2004, 2008). Estudos recentes demonstraram que cordeiros de 6 a 9 meses de idade secretam o vírus com uma maior frequência e maior quantidade, representando um risco maior para a transmissão dos vírus que os animais adultos (Li et al. 1998, 2004).

A apresentação clínica dos animais afetados nos 14 focos estudados foi consistente com relatos anteriores de FCM em bovinos (Rech et al. 2005, Barros et al. 2006, Radostitis et al. 2007). Os sinais mais observados estavam relacionados à cabeça e olho (com opacidade da córnea e profusa exsudação mucopurulento nasal e ocular como sinais mais frequentes), e à síndrome neurológica que foi observada em $80 \%$ dos relatos. Os achados de necropsia mais freqüentem foram opacidade bilateral da córnea e lesões inflamatórias nas mucosas. A histopatología permitiu a confirmação do diagnóstico predominando as lesões de panvasculite necrótica sistêmica, em concordância com o relatado na literatura (Rech et al. 2005, Barros et al. 2006, Radostits et al. 2007).

Através da PCR foi se capaz de confirmar a presença do agente etiológico da FCM em blocos de parafina de teci- 
dos armazenados desde 1999 nos arquivos do laboratório. A ocorrência de resultados falsos negativos nesta técnica pode se dever ao tempo de fixação em formol, tamanho e região do DNA amplificado (Matsubayashi et al. 1998). Desta forma, o diagnóstico baseado em nos sinais clínicos, lesões macro e microscópica são essenciais no diagnostico de FCM (Rech et al. 2005, Macêdo et al. 2007).

\section{CONCLUSÕES}

FCM está presente no Uruguai sendo os casos descritos principalmente na região norte do país em bovinos de corte.

Dada a sua apresentação clínica-epidemiológica a FCM é importante para o diagnóstico diferencial com as doenças que são encontradas atualmente nas campanhas sanitárias nacionais, como a febre aftosa, encefalopatia espogiforme dos bovinos e raiva (Días 2008).

\section{REFERÊNCIAS}

Alcaraz A., Warren A., Jackson C., Gold J., McCoy M., Cheong S.H., Kimball S., Sells S., Taus N.S., Divers T. \& Li H. 2009. Naturally occurring sheep-associated malignant catarrhal fever in North American pigs. J. Vet. Diagn. Invest. 21:250-253.

Barros C.S.L., Driemeier D., Dutra I.S. \& Lemos R.A.A. 2006. Doenças do Sistema Nervoso de Bovinos no Brasil. Vallée, Montes Claros, MG. 207p.

Campero C.M., Hecker Y., Odriozola E., Odeón A. \& Cantón G. 2008. Estudio retrospectivo de posibles casos de fiebre catarral maligna en bovinos. Revta Med. Vet., B. Aires, 89(4):140. (Resumo)

Censo Estadístico Agropecuario DIEA, MGAP 2011. Disponível em <http://www.mgap.gub.uy/portal/hgxpp001.aspx?7,5,583,0,S,0,MNU; E;27;7;MNU>

Davison A.J., Eberle R., Ehlers B., Hayward G.S., McGeoch D.J., Minson A.C., Pellett P.E., Roizman B., Studdert M.J. \& Thiry E. 2009. The order Herpesvirales. Arch. Virol. 154:171-177.

Dewals B.G. \& Vanderplasschen A. 2011. Malignant catarrhal fever induced by Alcelaphine herpesvirus 1 is characterized by an expansion of activated $\mathrm{CD}^{+}{ }^{+} \mathrm{CD} 8^{+} \mathrm{CD} 4 \mathrm{~T}$ cells expressing a cytotoxic phenotype in both lymphoid and non-lymphoid tissues. Vet. Res. 42:95.

Días L.E. 2008. Diagnóstico diferencial de fiebre aftosa en Uruguay, p.5167. In: Días L.E. (Ed.), Diagnóstico Diferencial en Fiebre Aftosa: historia del control y la erradicación en Uruguay. Capital Intelectual S.A., Buenos Aires.

Dutra F. 2009. Archivo Veterinario del Este. 3o trimestre. Disponível em <http://www.mgap.gub.uy/DGSG/DILAVE/Laboratorios/Archivo $\% 20$ Veterinario\%20del\%20Este\%20-\%20Año\%20I\%20№\%202.pdf>

Dutra F. 2010a. Análisis geográfico de la fiebre catarral maligna en bovinos de Uruguay y su asociación con el ovino. XXXVII Jornadas Uruguayas de Buiatría, Paysandú, p.162-163.
Dutra F. 2010b. Archivo Veterinario del Este 4o trimestre. 2009. Disponível em <http://www.mgap.gub.uy/DGSG/DILAVE/Laboratorios/Archivo\%20Veterinario\%20del\%20Este\%20-\%204T_2009.pdf>

Hänichen T., Reid H.W., Wiesner H. \& Hermanns W. 1998. Malignant catarrhal fever in zoo ruminants (English Abstract). Tierärztl. Prax., Grosstiere Nutztiere 26(5):294-300.

Hüssy D., Janett F., Albini S., Stäuber N., Thun R. \& Ackermann M. 2002. Analysis of the pathogenetic basis for shedding and transmission of ovine gamma herpesvirus 2. J. Clin. Microbiol. 40(12):4700-4704.

Li H., Snowder G., O’Toole D. \& Crawford T.B. 1998. Transmission of ovine herpesvirus 2 in lambs. J. Clin. Miciobiol. 36(1):223-226.

Li H., Keller J., Knowles D.P. \& Crawford T.B. 2001. Recognition of another member of the malignant catarrhal fever virus group: An endemic gammaherpesvirus in domestic goats. J. Gen. Virol. 82:227-232.

Li H., Taus N.S., Lewis G.S., Kim O., Traul D.L. \& Crawford T.B. 2004. Shedding of ovine herpesvirus 2 in sheep nasal secretions: the predominant mode of transmission. J. Clin. Microbiol. 42(12):5558-5564.

Li H., Taus N.S., Jones C., Murphy B., Evermann J.F. \& Crawford T.B. 2006. A devastating outbreak of malignant catarrhal fever in a bison feedlot. J. Vet. Diagn. Invest. 8:119-123.

Li H., Karney G., O’Toole D. \& Crawford T.B. 2008. Long distance spread of malignant catarrhal fever virus from feedlot lambs to ranch bison. Can. Vet. J. 49:183-185.

Macêdo J.T.S.A., Riet-Correa F., Simões S.V.D., Dantas A.F.M. \& Nobre V.M.T. 2007. Febre catarral maligna em bovinos na Paraíba. Pesq. Vet. Bras. 27(7):277-281.

Matsubayashi H., Watanabe H., Nishikura K., Ajioka Y., Maejima T., Kijima H. \& Saitoh T. 1998. Advantages of immunostaining over DNA analysis using PCR amplification to detect p53 abnormality in long-term formalin-fixed tissues of human colorectal carcinomas. J. Gastroenterol. 33:662-669

Mendonça F.S., Dória R.G.S., Schein F.B., Freitas S.H., Nakazato L., Boabaid F.M., Paula D.A.J., Dutra V. \& Colodel E.M. 2008. Febre catarral maligna em bovinos no Estado de Mato Grosso. Pesq. Vet. Bras. 28(3):155-160.

Plowright W., Ferris R.D. \& Scott G.R. 1960. Blue Wildebeest and the aetiological agent of bovine malignant catarrhal fever. Nature 188:11671169.

Radostits O.M., Gay C.C., Hinchcliff K.W. \& Constable P.D. 2007. Diseases associated with viruses and Chlamydia, p.3-37. In: Ibid. (Eds), Veterinary Medicine. $10^{\text {th }}$ ed. Saunders Elsevier, London.

Rech R.R., Schild A.L., Driemeier D., Garmatz S.L., Oliveira F.N., Riet-Correa F. \& Barros C.S.L. 2005. Febre catarral maligna em bovinos no Rio Grande do Sul: epidemiologia, sinais clínicos e patologia. Pesq. Vet. Bras. 25(2):97-105.

Schultheiss P.C., Collins J.K., Spraker T.R. \& DeMartini J.C. 2000. Epizootic malignant catarrhal fever in three bison herds: differences from cattle and association with ovine herpesvirus-2. J. Vet. Diagn. Invest. 12:497502.

Taus N.S., Schneider D.A., Oaks J.L., Yan H., Gailbreath K.L., Knowles D.P. \& Li H. 2010. Sheep (Ovis aries) airway epithelial cells support ovine herpesvirus 2 lytic replication in vivo. Vet. Microbiol. 154:47-53. 